Features of borderline personality disorder as a mediator of the relation between childhood traumatic experiences and psychosis-like experiences in patients with mood disorder

Baryshnikov, llya

2018-03

Baryshnikov , I , Aaltonen , K , Suvisaari , J , Koivisto , M , Heikkinen , M , Joffe , G \& Isometsä , E 2018 , ' Features of borderline personality disorder as a mediator of the relation between childhood traumatic experiences and psychosis-like experiences in patients with mood disorder ' , European Psychiatry , vol. 49 , pp. 9-15 . https://doi.org/10.1016/j.eurpsy.2017.12.005

http://hdl.handle.net/10138/300576

https://doi.org/10.1016/j.eurpsy.2017.12.005

publishedVersion

Downloaded from Helda, University of Helsinki institutional repository.

This is an electronic reprint of the original article.

This reprint may differ from the original in pagination and typographic detail.

Please cite the original version. 
Original article

\title{
Features of borderline personality disorder as a mediator of the relation between childhood traumatic experiences and psychosis-like experiences in patients with mood disorder
}

\author{
Ilya Baryshnikov ${ }^{a}$, Kari Aaltonen ${ }^{a, c}$, Jaana Suvisaari, ${ }^{a}$, , Maaria Koivisto $^{a}$, \\ Martti Heikkinen ${ }^{a}$, Grigori Joffe ${ }^{a}$, Erkki Isometsä ${ }^{a, *}$ \\ a Department of Psychiatry, University of Helsinki and Helsinki University Hospital, P.O. Box 22, 00014, Finland \\ ${ }^{\mathrm{b}}$ National Institute for Health and Welfare, Department of Social Services and Health Care, Mental Health Unit, FI-00271, Helsinki, Finland \\ ${ }^{\mathrm{c}}$ Department of Psychiatry, University of Helsinki and Helsinki University Hospital, P.O. Box 22 (Välskärinkatu 12 A), 00014, Finland
}

\section{A R T I C L E I N F O}

\section{Article history:}

Received 16 October 2017

Received in revised form 29 November 2017

Accepted 1 December 2017

Available online 30 January 2018

\section{Keywords:}

Borderline personality disorder

Psychotic-like symptoms

Childhood traumatic experiences

Mediation analysis

\begin{abstract}
A B S T R A C T
Background: Psychosis-like experiences (PEs) are common in patients with non-psychotic disorders. Several factors predict reporting of PEs in mood disorders, including mood-associated cognitive biases, anxiety and features of borderline personality disorder (BPD). Childhood traumatic experiences (CEs), often reported by patients with BPD, are an important risk factor for mental disorders. We hypothesized that features of BPD may mediate the relationship between CEs and PEs. In this study, we investigated the relationships between self-reported PEs, CEs and features of BPD in patients with mood disorders. Methods: As part of the Helsinki University Psychiatric Consortium study, McLean Screening Instrument (MSI), Community Assessment of Psychic Experiences (CAPE-42) and Trauma and Distress Scale (TADS) were filled in by patients with mood disorders $(n=282)$ in psychiatric care. Correlation coefficients between total scores of scales and their dimensions were estimated, multiple regression and mediation analyses were conducted.

Results: Total scores of MSI correlated strongly with scores of the CAPE-42 dimension "frequency of positive symptoms" ( $\mathrm{rho}=0.56 ; \mathrm{p} \leq 0.001)$ and moderately with scores of TADS ( $\mathrm{rho}=0.4 ; \mathrm{p} \leq 0.001$ ). Total score of MSI and its dimension "cognitive symptoms", including identity disturbance, distrustfulness and dissociative symptoms, fully mediated the relation between TADS and CAPE-42. Each cognitive symptom showed a partial mediating role (dissociative symptoms $43 \%(\mathrm{CI}=25-74 \%)$; identity disturbance $40 \%(\mathrm{CI}=30-73 \%)$; distrustfulness $18 \%(\mathrm{CI}=12-50 \%)$ ).

Conclusions: Self-reported cognitive-perceptual symptoms of BPD fully mediate, while affective, behavioural and interpersonal symptoms only partially mediate the relationships between CEs and PEs. Recognition of co-morbid features of BPD in patients with mood disorders reporting PEs is essential.
\end{abstract}

(C) 2017 Elsevier Masson SAS. All rights reserved.

\section{Introduction}

Psychosis-like experiences (PEs) are common both in the general population $[1,2]$ and in patients with non-psychotic mental disorders [3-8]. Individuals with mood and anxiety disorders tend to report PEs more often than healthy individuals [9]. Numerous

\footnotetext{
* Corresponding author at: Department of Psychiatry, P.O. Box 22 (Välskärinkatu 12 A), 0014, University of Helsinki, Finland.

E-mail addresses: ilya.baryshnikov@hus.fi (I. Baryshnikov), kari.aaltonen@helsinki.fi (K. Aaltonen), jaana.suvisaari@thl.fi (J. Suvisaari), maaria.koivisto@fimnet.fi (M. Koivisto), martti.heikkkinen@hus.fi (M. Heikkinen), grigori.joffe@hus.fi (G. Joffe), erkki.isometsa@helsinki.fi, erkki.isometsa@hus.fi (E. Isometsä).
}

studies have indicated that presence of PEs in non-psychotic disorders, such as mood and anxiety disorders, is associated with higher risk of suicidal thoughts and suicidal behaviour [10], psychological distress, higher co-morbidity and worse treatment outcomes [11-13]. Moreover, subthreshold PEs are more prevalent than full-blown psychotic symptoms $[14,15]$.

We recently demonstrated that PEs are highly prevalent in patients with unipolar depression and bipolar disorder treated in psychiatric care [16]. Several factors tend to predict reporting of PEs such as mood symptoms, anxiety symptoms and self-reported features of co-morbid personality disorders, including borderline personality disorder (BPD).

Features of BPD are common in patients with mood disorders [17-19], and they are clinically relevant even if self-reported [20]. 
Besides the well-known categorical co-morbidity [21] between BPD and mood disorders, there is also marked dimensional overlap between these conditions [22-25]. Transient, stress-related paranoid ideation or severe dissociative symptoms are among the diagnostic criteria of BPD [26]. These symptoms of BPD in patients with mood disorder are likely associated with higher psychological distress, functional impairments and worse treatment outcome [20,27,28]. Moreover, simultaneous BPD features in patients with ultra-high risk (UHR) for psychosis were associated with a wider range of reported PEs than in UHR patients without BPD features [29]. However, whether concurrent BPD is associated with higher risk for development of psychosis remains uncertain [30]. Partially overlapping neurobiological mechanisms of psychosis and BPD probably underlie phenomenological similarities between BPD and psychosis [31].

Childhood traumatic experiences (CEs) are an aetiological factor contributing to development of several mental disorders, including mood disorders, psychosis and BPD [32-40]. Both patients with BPD and UHR report CEs often, and especially sexual abuse was suggested to contribute to development of psychosis [41] and BPD [42,43]. Our previous study revealed a high prevalence of self-reported CEs in patients with mood disorders [17]. Subjects with a history of CEs, especially sexual abuse, tend to report a higher level of both dissociative $[44,45]$ and psychotic symptoms [46,47]. However, the causality and exact mechanisms linking CEs and various psychiatric disorders remain to be elucidated $[38,48,49]$. Some authors have even postulated that dissociative symptoms might be a mediator between CEs and psychotic symptoms [50-54]. Other authors have found no mediational role of dissociative or affective symptoms in the relationship between CEs and transition to psychosis in UHS patients [55].

The majority of studies investigating relationships between CEs and PEs have been conducted in non-clinical populations, UHR patients or patients with psychosis. However, clinically relevant PEs are present also in patients with mood disorders. Some authors propose that PEs reflect the continuum of psychosis [56] or may be associated with concurrent personality pathology [16]. Given that BPD and PEs probably share similar aetiological factors in the form of CEs, we hypothesized that features of BPD in patients with mood disorders may mediate the relationship between CEs and selfreported PEs. Thus, we aimed to a) examine whether features of co-morbid BPD mediate the relation between CEs and PEs; b) define specific symptoms of BPD correlated with PEs; and c) examine the mediational role of specific symptom clusters of BPD in relationships between CEs and PEs in patients with mood disorders.

\section{Methods}

The methodology of the HUPC study has been reported in detail elsewhere [57,58].

\subsection{Helsinki university psychiatric consortium (HUPC)}

This investigation is part of the HUPC study. The study protocol was approved by the Ethics Committee of Helsinki University Central Hospital on 28 August 2010.

\subsection{Setting}

The study was conducted between 12.1.2011 and 20.12.2012 in 10 community mental health centres, three psychiatric inpatient units and one day-hospital, all offering specialized secondary public mental health services in the metropolitan area of Helsinki.

\subsection{Sampling}

Inclusion criteria were patients' age $\geq 18$ years and provision of informed consent. Patients with mental retardation, neurodegenerative disorders and insufficient Finnish language skills were excluded. Stratified patient sampling selection was performed [58]. Of the 902 eligible patients with mood, neurotic or personality disorders, 372 refused to participate and 216 were lost for other reasons. In addition, 31 patients with other lifetime diagnoses were excluded.

\subsection{Clinical diagnoses}

The validity of the clinical diagnoses assigned by the attending physicians was critically evaluated by the authors by re-examining all available information from patient records. The validated clinical diagnoses were based on the ICD-10-DCR [59]. Lifetime principal diagnosis was assigned.

\subsection{Description of patients}

Altogether 282 patients participated in the study. Their mean age was $42.2 \pm 13.1$ years, and 209 (74.1\%) were female. There were 183 patients with unipolar depression (UD, F32-F33) (mean age $41.4 \pm 13.3$ years) and 99 with bipolar disorder (BD, F31) (mean age $43.7 \pm 12.7$ years). Seventeen patients with BP had co-morbid BPD; among patients with UD, 39 had co-morbid BPD. In terms of age and gender, sample distribution did not differ from patients with the same diagnoses treated in 2011 and 2012 in psychiatric care organizations.

\subsection{Trauma and distress scale (TADS)}

TADS is a self-report questionnaire that measures childhood trauma and distress experiences through 43 items [60]. The TADS items measure symptoms in five main domains: emotional abuse, physical abuse, sexual abuse, emotional neglect and physical neglect. Each item is rated on a four-point Likert scale from 1 to 4 . TADS has been validated in Finland [61].

\subsection{McLean screening instrument (MSI)}

The MSI is a ten-item questionnaire designed according to DSM-IV diagnostic criteria to screen for BPD [62]. It has been translated into Finnish and validated in Finland [63]. Each item requires a "yes/no" response. Each positive item indicates the presence of BPD symptoms. We have allocated the items of MSI into four groups: "cognitive symptoms" (including items "identity disturbance", "distrustfulness" and "dissociative symptoms"), "behavioural symptoms" (i.e. "impulsivity" and "suicidal behaviour"), "affective symptoms" (i.e. "mood instability", "increased anger" and "feeling of emptiness") and "interpersonal symptoms" (i.e. "troubled relationships" and "fear of abandonment") [64].

\subsection{Community assessment of psychic experiences (CAPE-42)}

The CAPE-42 is a self-reported questionnaire that measures lifetime psychotic experiences by using 42 items. The items measure symptoms in three main domains: positive symptoms (20 items), negative symptoms (14 items) and depression symptoms ( 8 items). Each item is rated on a four-point Likert scale from 1 to 4 for both symptom frequency and the degree of distress experienced due to the symptom. 


\subsection{Statistical analysis}

The correlation analysis was executed between scales' total scores and their dimensions. As the total scores of the MSI correlated strongly with a dimension "frequency of positive symptoms" of the CAPE-42, we conducted a principal components analysis, employing a Varimax orthogonal rotation with a forced two-component solution in order to examine distribution of the items between two scales. The majority of the MSI and CAPE42 items predictably loaded on their respective components, indicating that despite a partial overlap between the scales, a greater part of their items are non-overlapping (data available upon request). Hierarchical multiple regression analysis (HMRA) was conducted to assess factors predicting reporting of PEs. To account for the possible effect of age and sex on the reporting of PEs, model 1 included these variables. Due to moderate correlations between the scores of TADS and MSI, they were placed in different models - model 2 (age, sex, TADS) and model 3 (MSI). In addition, the separate items of the MSI were included in model 3 of another HMRA to examine items of MSI predicting selfreported PEs. Mediation analysis was conducted using the bootstrapping method with bias-corrected confidence estimates [65]. The independent variable was TADS, the dependent variable was the dimension "frequency of positive symptoms" score of CAPE42 and the mediator variable was MSI. Three separate mediation analyses were performed with different mediators: the total score of MSI; the dimensions of MSI; and the item "dissociative symptoms" of the MSI. The 95\% confidence interval of the indirect effects was obtained with 5000 bootstrap resamples [66]. The analyses were performed by using SPSS (IBM Corp. Released 2013).

\section{Results}

Total scores of the CAPE-42 "frequency of positive symptoms" scale, TADS and MSI are shown in previous reports [17,67].

\subsection{Correlation analyses}

a.) The total scores of TADS correlated moderately with both total scores of MSI $(r h o=0.4 ; \mathrm{p} \leq 0.001)$ and the "frequency of positive symptoms" scale of CAPE- $42(r h o=0.29 ; \mathrm{p} \leq 0.001)$. The total scores of MSI and the "frequency of positive symptoms" scale of CAPE-42 were strongly correlated (rho $=0.56 ; \mathrm{p} \leq 0.001)$. Specifically, a strong correlation emerged between the MSI dimension "cognitive symptoms" and CAPE-42 "positive symptoms"; a moderate correlation between MSI "affective symptoms" and "behavioural symptoms" and CAPE-42 "positive symptoms"; and a weak correlation between MSI "interpersonal symptoms" and CAPE-42 "positive symptoms" (see Fig. 1).

b.) The specific items of MSI, such as "dissociative symptoms", "distrustfulness" and "identity disturbance", correlated moderately with the total score of "frequency of positive symptoms" of CAPE- $42\left(\mathrm{r}_{\mathrm{pb}}=0.50 ; 0.40\right.$; and 0.42 , respectively; $\mathrm{p} \leq 0.01$ ) (see Fig. 2).

c.) All dimensions of TADS correlated moderately with the total score of MSI and the CAPE-42 dimension "frequency of positive symptoms" ( $\mathrm{r}_{\mathrm{s}}$ varied between 0.202 and $0.375 ; \mathrm{p} \leq 0.01$ ) (see Table 1).

\subsection{HMRA predicting frequency of psychosis-like experiences from TADS and MSI}

In Step 1 (variables of age and sex) $(\mathrm{R} 2=0.061, \mathrm{~F}(2,248)=8.0$, $\mathrm{p}<0.001$ ), only age had significant weight. The addition of TADS (Step 2) led to a significant increase in R2 by $0.07, \mathrm{~F}(1,247)=11.9$, $\mathrm{p}<0.001$, with significant weights for age and TADS. The addition of MSI (Step 3) led to a significant increase in R2 by 0.173 , $\mathrm{F}(1,246)=26.3, \mathrm{p}<0.001$, with significant weight only for MSI ( $\beta$ values not shown, data available on request). The variance inflation factors (VIF) varied between 1.00 and 1.35 .

\subsection{HMRA predicting frequency of psychosis-like experiences from items of MSI}

Step 1 and step 2 were similar to the previously presented HMRA. In step 3, only items "dissociative symptoms", "distrustfulness" and "identity disturbance" had significant weights $(\beta=0.3$, $\mathrm{p}<0.001 ; \beta=0.12, \mathrm{p}<0.05 ; \beta=0.13, \mathrm{p}<0.05$, respectively) (see Table 2). The VIF varied between 1.00 and 1.41 .

\subsection{Mediation analysis}

\subsubsection{Mediating role of MSI total scores}

The indirect effect of TADS on positive symptoms (CAPE-42) through MSI was significant $(B=0.11 ; t(251)=4.3 ; C I=0.05$ to 0.11). However, the direct effect of TADS on CAPE-42 became insignificant $(B=0.03 ; t(251)=1.2 ; p=0.25)$ when controlling for MSI, thus indicating a full mediation (see Fig. 3).

\subsubsection{Mediation analysis of MSI dimensions}

A mediating role of the four MSI dimensions was specified. The dimension "cognitive symptoms" provided a full mediation on the relationship between TADS and CAPE-42. The dimensions

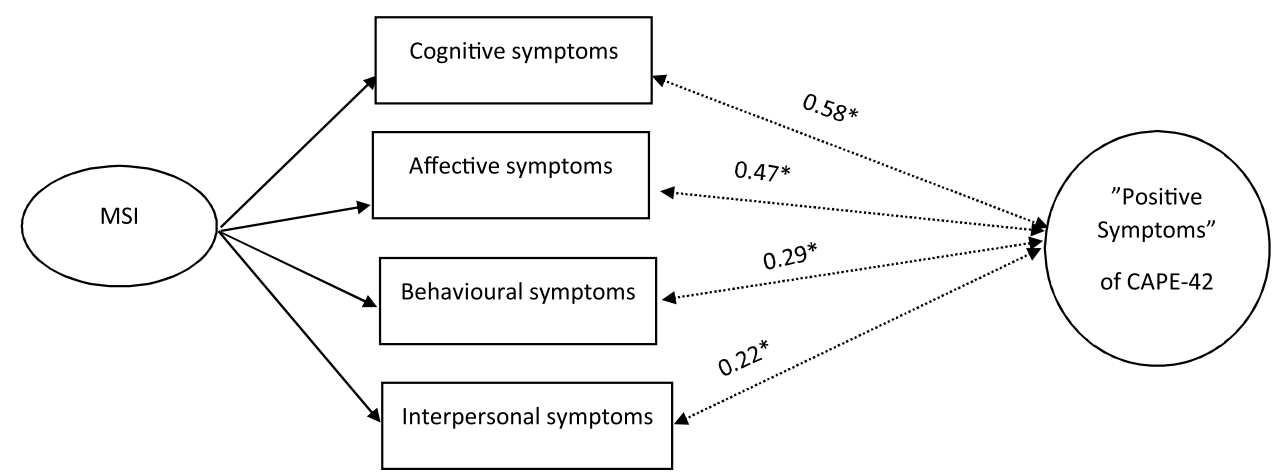

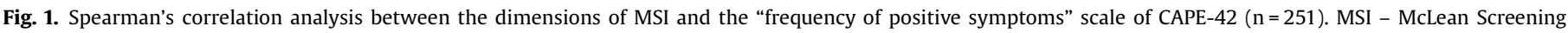
Instrument; CAPE-42-Community Assessment of Psychic Experiences. * $\mathrm{p} \leq 0.01$. 


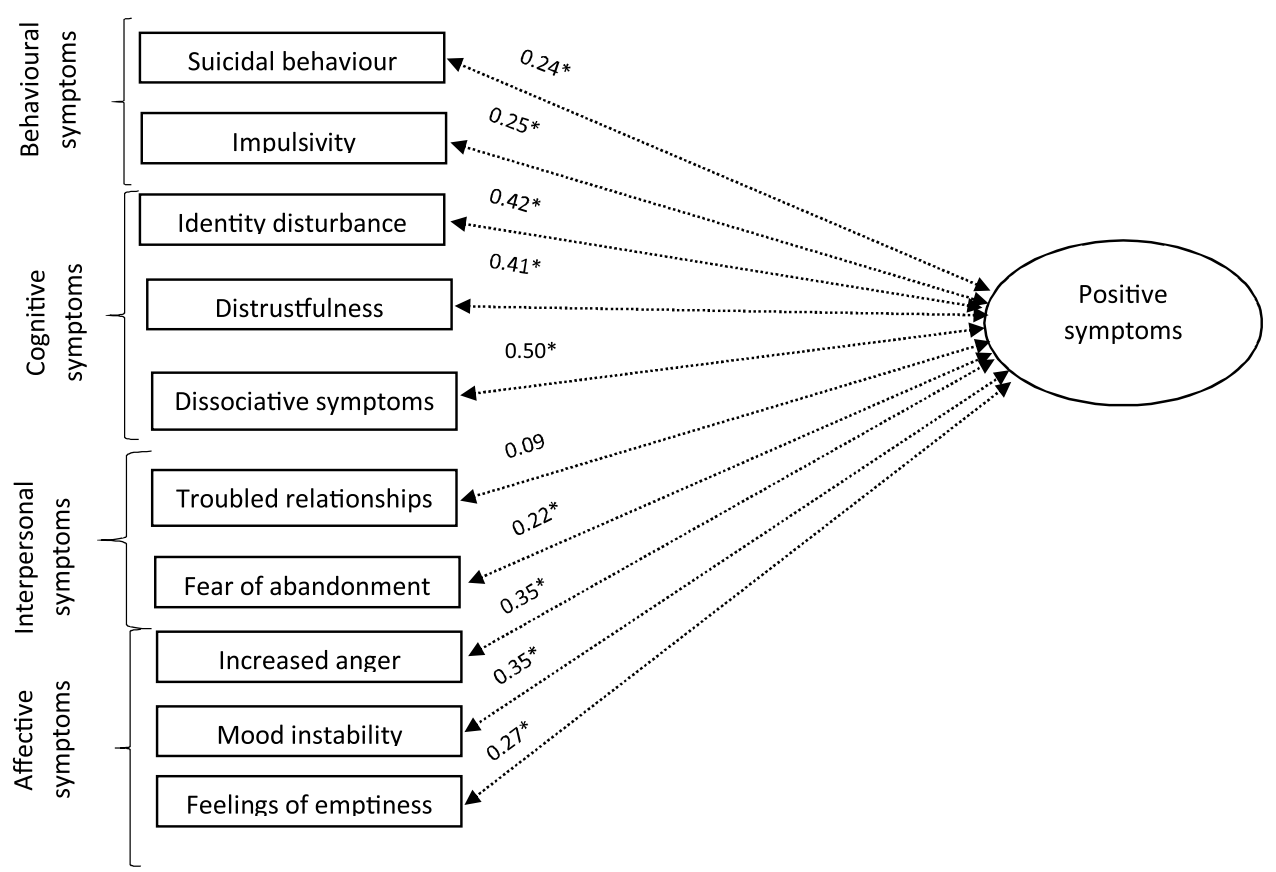

Fig. 2. Point-biserial correlations $r_{p b}$ between items of MSI and total score of the "frequency of the positive symptoms" scale of CAPE- 42 ( $\mathrm{n}=251$ ).

Table 1

Spearman's correlation analysis between the dimensions of TADS, MSI total score and the frequency of positive symptoms scale of CAPE-42 $(n=251)$.

\begin{tabular}{lcc}
\hline TADS dimensions & MSI total score & CAPE-42; frequency of positive symptoms \\
\hline Emotional abuse & $0.375^{*}$ & $0.289^{*}$ \\
Physical abuse & $0.309^{*}$ & $0.257^{*}$ \\
Sexual abuse & $0.272^{*}$ & $0.226^{*}$ \\
Emotional neglect & $0.345^{*}$ & $0.202^{*}$ \\
Physical neglect & $0.343^{*}$ & $0.254^{*}$ \\
\hline
\end{tabular}

MSI - McLean Screening Instrument; TADS - Trauma and Distress Scale; CAPE-42Community Assessment of Psychic Experiences.

$\mathrm{p} \leq 0.01$.

“affective symptoms", "behavioural symptoms" and "interpersonal symptoms" demonstrated a partial mediation on the relationship between TADS and CAPE-42 (40\% CI 29-75\%; 10\% CI 8-37\%; 8\% CI 6-38\%, respectively) (see Supplementary Figs. 1-4).

\subsubsection{Mediation analysis of specific MSI items "dissociative} symptoms", "distrustfulness" and "identity disturbance"

The indirect effect of TADS on the "frequency of positive symptoms" of the CAPE-42 separately through the distinct MSI items "dissociative symptoms", "distrustfulness" and "identity disturbance" was significant. Thus, $43 \%(\mathrm{CI}=25-74 \%)$ of the association between TADS and the "frequency of positive symptoms" of the CAPE-42 was mediated by MSI "dissociative symptoms", $40 \%(\mathrm{CI}=30-73 \%)$ by "identity disturbance" and $18 \%$ $(\mathrm{CI}=12-50 \%)$ by "distrustfulness" (See Supplementary Figs. $5-7$ ).

\section{Discussion}

Problematic boundaries between BPD, particularly its dissociative and transient paranoid symptoms, and psychosis have long been a topic of extensive debates [51-56]. Both disorders partially share phenomenological features as well as an aetiological factor (childhood traumatic experiences (CEs)). However, the relationships between CEs, features of BPD and self-reported PEs in patients with mood disorders have not been investigated. Our study filled this gap by demonstrating a complete mediational role of self-reported features of BPD in the relationship between CEs and PEs in patients with unipolar depression and bipolar disorder. In other words, in patients with mood disorders the association between self-reported CEs and PEs is completely attributed to selfreported symptoms of BPD. Features reflecting cognitive symptoms of patients with BPD (i.e. "dissociative symptoms", "distrustfulness" and "identity disturbance") mediated fully the relationship between CEs and PEs, whereas symptoms of affective and behavioral dysregulation as well as interpersonal symptoms of BPD only partially mediated this relationship.

Table 2

Hierarchical multiple regression analysis in predicting frequency of the positive symptoms scale of CAPE-42 from age, sex, TADS, and the items of MSI in patients with mood disorders $(n=251)$.

\begin{tabular}{|c|c|c|c|c|c|c|}
\hline \multirow[b]{2}{*}{ Variable } & \multicolumn{2}{|l|}{ Step 1} & \multicolumn{2}{|l|}{ Step 3} & \multicolumn{2}{|l|}{ Step 3} \\
\hline & B & $\beta$ & B & & B & $\beta$ \\
\hline Constant & \multicolumn{2}{|c|}{$35.2^{* *}$} & \multicolumn{2}{|c|}{$33.3^{* *}$} & \multicolumn{2}{|c|}{$25.7^{* *}$} \\
\hline Age & $-0.14^{* *}$ & $-0.25^{* * *}$ & $-0.13^{* *}$ & $-0.24^{* *}$ & -0.04 & -0.79 \\
\hline Sex & -0.58 & -0.04 & -1.24 & -0.8 & -1.00 & -0.65 \\
\hline TADS & & & $0.10^{* *}$ & $0.26^{* *}$ & 0.039 & 0.09 \\
\hline Troubled relationships & & & & & -1.3 & -0.08 \\
\hline Suicidal behaviour & & & & & -0.3 & -0.2 \\
\hline Impulsivity & & & & & 0.4 & 0.27 \\
\hline Mood instability & & & & & 2.0 & 0.14 \\
\hline Increased anger & & & & & 1.3 & 0.95 \\
\hline Distrustfulness & & & & & $1.9^{*}$ & $0.13^{*}$ \\
\hline Dissociative symptoms & & & & & $4.2^{* *}$ & $0.3^{* * *}$ \\
\hline Feeling of emptiness & & & & & 0.15 & 0.01 \\
\hline Identity disturbance & & & & & $1.8^{*}$ & $0.13^{*}$ \\
\hline Fear of abandonment & & & & & 1.8 & 0.13 \\
\hline $\mathrm{R} 2$ & \multicolumn{2}{|c|}{0.061} & \multicolumn{2}{|c|}{0.127} & \multicolumn{2}{|c|}{0.39} \\
\hline$\Delta \mathrm{R} 2$ & \multicolumn{2}{|c|}{0.061} & \multicolumn{2}{|c|}{0.066} & \multicolumn{2}{|c|}{0.25} \\
\hline $\mathrm{F}$ & \multicolumn{2}{|c|}{$8.0^{* *}$} & \multicolumn{2}{|c|}{$11.9^{* *}$} & \multicolumn{2}{|c|}{$11.1^{* * *}$} \\
\hline$\Delta \mathrm{F}$ & \multicolumn{2}{|c|}{$8.0^{* *}$} & \multicolumn{2}{|c|}{$18.6^{* *}$} & \multicolumn{2}{|c|}{$9.6^{* *}$} \\
\hline
\end{tabular}

Step 1 (age, sex); Step 2 (age, sex, TADS); Step 3 (age, sex, TADS, items of MSI); B - unstandardized coefficients; $\beta$ - standardized coefficients; MSI - McLean Screening Instrument; TADS - Trauma and Distress Scale; CAPE-42-Community Assessment of Psychic Experiences.

${ }^{*} \mathrm{p}<0.05$. 


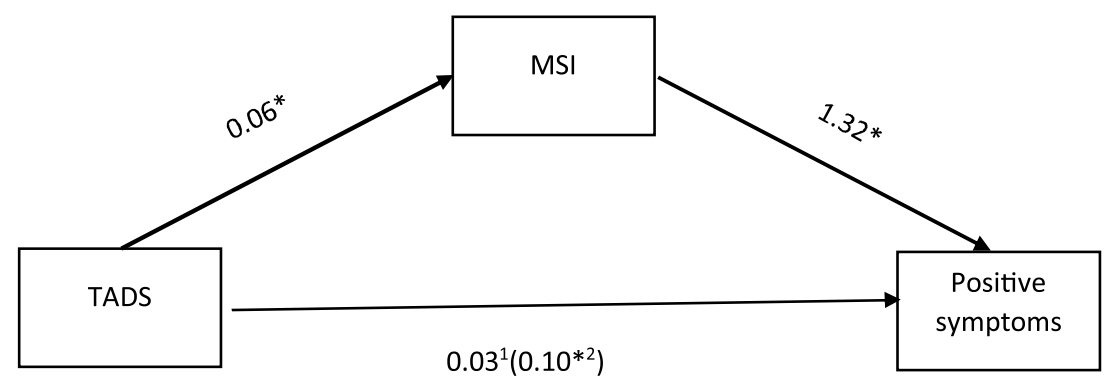

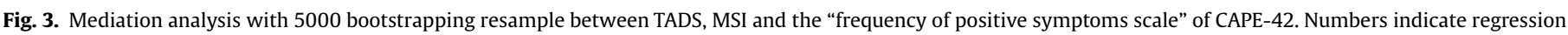
coefficients (B). MSI - McLean Screening Instrument; CAPE-42-Community Assessment of Psychic Experiences; TADS - Trauma and Distress Scale.

${ }^{*} \mathrm{p} \leq 0.001$.

${ }^{1}$ indicates the direct effect of TADS on the "frequency of the positive symptoms scale" when controlling for MSI.

${ }^{2}$ indicates the total effect of TADS on the "frequency of the positive symptoms scale".

In addition, our study defined a mediational role of specific selfreported features of BPD: $43 \%$ of the relation between self-reported CEs and PEs was mediated by self-reported dissociative symptoms of BPD, $40 \%$ by self-reported identity disturbance and $18 \%$ by selfreported distrustfulness. Another major finding of the study is, as expected, a moderate correlation between the self-reported features of BPD "dissociative symptoms", "identity disturbance" and "distrustfulness" with the frequency of self-reported PEs in patients with mood disorders. Moreover, these self-reported features of BPD independently predicted the self-reported PEs in patients with mood disorders.

The strengths and limitations of the HUPC study have been discussed in detail elsewhere [17,58], but are briefly outlined below. To the best of our knowledge, this is the first study providing a detailed analysis of the associations between self-reported features of BPD, CEs and psychosis-like experiences in mood disorder patients. The investigation was undertaken with a relatively large and representative sample of mood disorder patients recruited from specialized psychiatric care, and extensive data of self-reported symptoms and experiences was collected. Moreover, we examined a comprehensive set of self-reported data of CEs, an important factor in the aetiology of mood disorders, psychosis and BPD [32-40].

Some limitations of the study should be mentioned. First, the response rate was only $43 \%$. However, an analysis of representativeness indicated no significant differences in terms of age or sex between our cohort and the whole patient population within specialized psychiatric care of the catchment area (data not shown). Furthermore, in terms of demographic characteristics our cohort did not differ from screening-based representative cohorts from the same area $[68,69]$. Second, the clinical diagnoses were not verified with structured clinical diagnostic interviews. However, all patients had been diagnosed with mood disorders in specialized psychiatric settings, and all available information was re-evaluated by the authors. Third, the results of our study are based on selfreport scales. Numerous studies have shown that patients with mood disorders often demonstrate impairments in social cognition [70], autobiographical memory disruptions [71] and distortions in self-reflections [72]. Moreover, dissociative symptoms per se $[73,74]$ may affect a patient's ability to recall events in childhood. Fourth, it is important to note that the CAPE measures frequency of occurrence of PEs over the lifetime, not frequency or severity of PE symptoms during a distinct illness episode (psychotic mania or psychotic depression). Fifth, we assumed a causal relationship between self-reported CEs and PEs, to be tested in mediational analysis. However, a cross-sectional study does not allow determination of causality of these relationships, although a retrospectively assessed temporal sequence of exposures and outcomes is theoretically plausible. Sixth, we have not considered the potential impact of mood state on reporting of BPD features. Seventh, as shown in our previous studies [16,17,19,57], there is a phenomenological overlap between self-reported features of BPD and symptoms of mania, hypomania, depression and schizotypal personality disorder (SPD). A comprehensive clinical interview is needed to distinguish these mental disorders. Finally, a strong correlation between self-reported dissociative symptoms and frequency of psychosis-like symptoms may affect the results of the regression and mediation analyses to some extent. However, no multicollinearity problems was indicated.

The term "borderline" was initially introduced to emphasize the idea that patients with this pathology are "on the border" of psychosis [75,76]. However, more recent neurobiological and genetic studies have pointed to stronger associations of BPD with mood disorders than with psychotic disorders [77]. A high prevalence of PEs and dissociative symptoms reported by patients with BPD has been established [75,78-81,86]. Moreover, the more severe presentation of $\mathrm{BPD}$, the more likely patients report PEs [82]. In line with this, our study has shown a moderate correlation between self-reported features of BPD and frequency of selfreported PEs. Such self-reported features of BPD as "dissociative symptoms", "distrustfulness" and "identity disturbance" correlated stronger than others with the self-reported PEs, and independently predict PEs. Thus, the more often mood disorder patients report "dissociative symptoms", "distrustfulness" and "identity disturbance", the more likely they are also to report PEs.

The DSM-5 [26] emphasizes that PEs and dissociative symptoms in patients with BPD are transient, occurring for brief periods in situations related to affective shifts associated with the fear of abandonment and interpersonal disputes. It is important to note that both of the self-report questionnaires, MSI for BPD and CAPE-42 for PEs, include questions regarding lifetime symptoms. Consequently, it is impossible to know whether the PEs occurred only during psychotic mood episodes or during specific stressful situations or whether these self-reported PEs are associated with BPD, SPD or both.

Patients with a variety of mental disorders often report CEs [32-43]. In our previous study [17], patients with mood disorders reported CEs more often than non-psychiatric individuals investigated in an earlier study [61]. In addition, the mean score of the "sexual abuse" dimension of TADS was higher in patients with mood disorders than in individuals from the general population, but the same as in patients with clinical high risk for psychosis [83]. Congruent with this finding, we have shown a moderate correlation between all dimensions of TADS and self-reported PEs. 
However, not all patients exposed to CEs later develop BPD, and not all patients with BPD report CEs [48]. The same is true for psychosis [49].

We previously demonstrated that insecure attachment style mediated the relation between CEs and features of BPD in patients with mood disorders. Interestingly, other studies have shown a mediating role of insecure attachment style in the relationship between CEs and paranoia [52,84] and of dissociative symptoms in the relationship between CEs and auditory verbal hallucinations $[52,85]$. Our study demonstrated that self-reported features of $\mathrm{BPD}$, specifically those reflecting cognitive-perceptual distortions of BPD, fully mediated the relation between self-reported CEs and PEs in patients with mood disorders. Thus, the pathway between self-reported CEs and PEs in patients with mood disorders probably consists of, firstly, insecure attachment style and, secondly, self-reported BPD features. Therefore, a diagnosis of co-morbid BPD features is essential for clinically interpreting selfreported PEs in patients with mood disorders with a history of childhood adversities.

\section{Conclusion}

Recognition of co-morbid features of BPD in patients with mood disorders reporting PEs is essential. Self-reported features reflecting cognitive-perceptual distortions of patients with BPD, namely "dissociative symptoms", "identity disturbance" and "distrustfulness", moderately correlate and independently predict selfreported PEs in patients with mood disorders. The self-reported cognitive-perceptual symptoms of BPD fully mediated the relation between self-reported CEs and PEs, whereas affective, behavioural and interpersonal symptoms showed only a partial mediational effect. More specifically, $43 \%$ of the relation between self-reported CEs and PEs was mediated by self-reported dissociative symptoms, $40 \%$ by self-reported identity disturbance and $18 \%$ by self-reported distrustfulness. Thus, the mediational role of cognitive-perceptual symptoms of BPD is central.

\section{Appendix A. Supplementary data}

Supplementary data associated with this article can be found, in the online version, at https://doi.org/10.1016/j.eurpsy.2017.12.005.

\section{References}

[1] Verdoux H, van Os J. Psychotic symptoms in non-clinical populations and the continuum of psychosis. Schizophr Res 2002;54(March (1-2)):59-65.

[2] McGrath JJ, Saha S, Al-Hamzawi A, Alonso J, Bromet EJ, Bruffaerts R, et al. Psychotic experiences in the general population: a cross-national analysis based on 31,261 respondents from 18 countries. JAMA Psychiatry 2015;72(July (7)):697-705.

[3] DeVylder JE, Burnette D, Yang LH. Co-occurrence of psychotic experiences and common mental health conditions across four racially and ethnically diverse population samples. Psychol Med 2014;44(December (16)):3503-13.

[4] Hanssen MS, Bijl RV, Vollebergh W, van Os J. Self-reported psychotic experiences in the general population: a valid screening tool for DSM-III-R psychotic disorders? Acta Psychiatr Scand 2003;107(May (5)):369-77.

[5] Saha S, Scott J, Varghese D, McGrath J. Anxiety and depressive disorders are associated with delusional-like experiences: a replication study based on a national survey of mental health and wellbeing. BMJ Open 20122(May (3)), doi:http://dx.doi.org/10.1136/bmjopen, 2012-001001 Print 2012.

[6] Fusar-Poli P, Nelson B, Valmaggia L, Yung AR, McGuire P⿳亠丷. Comorbid depressive and anxiety disorders in 509 individuals with an at-risk mental state: impact on psychopathology and transition to psychosis. Schizophr Bull 2014;40(January (1)):120-31.

[7] Bortolon C, Raffard S. Self-reported psychotic-like experiences in individuals with obsessive-compulsive disorder versus schizophrenia patients: characteristics and moderation role of trait anxiety. Compr Psychiatry 2015;57 (February):97-105.

[8] Kelleher I, DeVylder JE. Hallucinations in borderline personality disorder and common mental disorders. Br J Psychiatry 2017;210(March (3)):230-1.

[9] Wigman JT, van Os J, Abidi L, Huibers MJ, Roelofs J, Arntz A, et al. Subclinical psychotic experiences and bipolar spectrum features in depression: association with outcome of psychotherapy. Psychol Med 2014;44(January (2)):325-36.

[10] DeVylder JE, Jahn DR, Doherty T, Wilson CS, Wilcox HC, Schiffman J, et al. Social and psychological contributions to the co-occurrence of sub-threshold psychotic experiences and suicidal behavior. Soc Psychiatry Psychiatr Epidemiol 2015;50(December (12)):1819-30.

[11] Kelleher I, Keeley H, Corcoran P, Lynch F, Fitzpatrick C, Devlin N, et al Clinicopathological significance of psychotic experiences in non-psychotic young people: evidence from four population-based studies. Br J Psychiatry 2012;201(1):26-32.

[12] Collip D, Wigman JT, Myin-Germeys I, Jacobs N, Derom C, Thiery E, et al. From epidemiology to daily life: linking daily life stress reactivity to persistence of psychotic experiences in a longitudinal general population study. PLoS One 2013;8(April (4)):e62688.

[13] DeVylder JE, Kelleher I. Clinical significance of psychotic experiences in the context of sleep disturbance or substance use. Psychol Med 2016;46(June (8)):1761-7.

[14] Linscott RJ, van Os J. An updated and conservative systematic review and metaanalysis of epidemiological evidence on psychotic experiences in children and adults: on the pathway from proneness to persistence to dimensional expression across mental disorders. Psychol Med 2013;43(June (6)):1133-49.

[15] Schultze-Lutter F, Renner F, Paruch J, Julkowski D, Klosterkotter J, Ruhrmann S. Self-reported psychotic-like experiences are a poor estimate of clinician-rated attenuated and frank delusions and hallucinations. Psychopathology 2014;47 (3):194-201.

[16] Baryshnikov I, Suvisaari J, Aaltonen K, Koivisto M, Melartin T, Naatanen P, et al. Self-reported psychosis-like experiences in patients with mood disorders. Eur Psychiatry 2017(February).

[17] Baryshnikov I, Joffe G, Koivisto M, Melartin T, Aaltonen K, Suominen K, et al Relationships between self-reported childhood traumatic experiences, attachment style, neuroticism and features of borderline personality disorders in patients with mood disorders. J Affect Disord 2017;210(March):82-9.

[18] Baryshnikov I, Suvisaari J, Aaltonen K, Koivisto M, Näätänen P, Karpov B, et al. Self-reported symptoms of schizotypal and borderline personality disorder in patients with mood disorders. Eur Psychiatry 2016;3(33):37-44.

[19] Baryshnikov I, Aaltonen K, Koivisto M, Näätänen P, Karpov B, Melartin T, et al. Differences and overlap in self-reported symptoms of bipolar disorder and borderline personality disorder. Eur Psychiatry 2015;30(8):914-9.

[20] Zimmerman M, Chelminski I, Young D, Dalrymple K, Martinez J. Does the presence of one feature of borderline personality disorder have clinical significance? implications for dimensional ratings of personality disorders. J Clin Psychiatry 2012;73(January (1)):8-12.

[21] Grant BF, Chou SP, Goldstein RB, Huang B, Stinson FS, Saha TD, et al. Prevalence, correlates, disability, and comorbidity of DSM-IV borderline personality disorder: results from the wave 2 national epidemiologic survey on alcohol and related conditions. J Clin Psychiatry 2008;69(April (4)):533-45.

[22] Grant BF, Chou SP, Goldstein RB, Huang B, Stinson FS, Saha TD, et al. Prevalence, correlates, disability, and comorbidity of DSM-IV borderline personality disorder: results from the wave 2 national epidemiologic survey on alcohol and related conditions. J Clin Psychiatry 2008;69(April (4)):533-45.

[23] Leichsenring F, Leibing E, Kruse J, New AS, Leweke F. Borderline personality disorder. Lancet 2011;377(January (9759)):74-84.

[24] Melartin TK, Rytsala HJ, Leskela US, Lestela-Mielonen PS, Sokero TP, Isometsa ET. Current comorbidity of psychiatric disorders among DSM-IV major depressive disorder patients in psychiatric care in the vantaa depression study. J Clin Psychiatry 2002;63(February (2)):126-34.

[25] Melartin T, Mantere O, Ketokivi M, Isometsa E. A prospective latent analysis study of axis I psychiatric co-morbidity of DSM-IV major depressive disorder. Psychol Med 2014;44(April (5)):949-59.

[26] American Psychiatric Association. The diagnostic and statistical manual of mental disorders. fifth edition American Psychiatric Association; 2013.

[27] Kleindienst N, Limberger MF, Ebner-Priemer UW, Keibel-Mauchnik J, Dyer A, Berger M, et al. Dissociation predicts poor response to dialectial behavioral therapy in female patients with borderline personality disorder. J Pers Disord 2011;25(August (4)):432-47.

[28] Zanarini MC, Laudate CS, Frankenburg FR, Reich DB, Fitzmaurice G. Predictors of self-mutilation in patients with borderline personality disorder: a 10-year follow-up study. J Psychiatr Res 2011;45(June (6)):823-8.

[29] Ryan J, Graham A, Nelson B, Yung A. Borderline personality pathology in young people at ultra high risk of developing a psychotic disorder. Early Interv Psychiatry 2015(March).

[30] Thompson A, Nelson B, Bechdolf A, Chanen AM, Domingues I, McDougall E, et al. Borderline personality features and development of psychosis in an 'ultra high risk' (UHR) population: a case control study. Early Interv Psychiatry 2012;6(August (3)):247-55.

[31] Witt SH, Streit F, Jungkunz M, Frank J, Awasthi S, Reinbold CS, et al. Genomewide association study of borderline personality disorder reveals genetic overlap with bipolar disorder, major depression and schizophrenia. Trans Psychiatry 2017;7(June (6)):e1155.

[32] Mayo D, Corey S, Kelly LH, Yohannes S, Youngquist AL, Stuart BK, et al. The role of trauma and stressful life events among individuals at clinical high risk for psychosis: a review. Front Psychiatry 2017;8(April):55.

[33] Ball JS, Links PS. Borderline personality disorder and childhood trauma: evidence for a causal relationship. Curr Psychiatry Rep 2009;11(February (11)):63-8. 
[34] Battle CL, Shea MT, Johnson DM, Yen S, Zlotnick C, Zanarini MC, et al. Childhood maltreatment associated with adult personality disorders: findings from the collaborative longitudinal personality disorders study. J Pers Disord 2004;18 (April (2)):193-211.

[35] Etain B, Henry C, Bellivier F, Mathieu F, Leboyer M. Beyond genetics: childhood affective trauma in bipolar disorder. Bipolar Disord 2008;10(December (8)):867-76.

[36] Kupfer DJ, Frank E, Phillips ML. Major depressive disorder: new clinical, neurobiological, and treatment perspectives. Lancet 2012;379(March (9820)):1045-55.

[37] Nanni V, Uher R, Danese A. Childhood maltreatment predicts unfavorable course of illness and treatment outcome in depression: a meta-analysis. Am J Psychiatry 2012;169(February (2)):141-51.

[38] Teicher MH, Samson JA. Childhood maltreatment and psychopathology: a case for ecophenotypic variants as clinically and neurobiologically distinct subtypes. Am J Psychiatry 2013;170(October (10)):1114-33.

[39] Brew B, Doris M, Shannon C, Mulholland C. What impact does trauma have on the at-risk mental state? A systematic literature review. Early Interv Psychiatry 2017(May)

[40] Vrijsen JN, van Amen CT, Koekkoek B, van Oostrom I, Schene AH, Tendolkar I. Childhood trauma and negative memory bias as shared risk factors for psychopathology and comorbidity in a naturalistic psychiatric patient sample. Brain Behav 2017;7(May (6)):e00693.

[41] Thompson AD, Nelson B, Yuen HP, Lin A, Amminger GP, McGorry PD, et al. Sexual trauma increases the risk of developing psychosis in an ultra high-risk prodromal population. Schizophr Bull 2014;40(May (3)):697-706.

[42] Yen S, Shea MT, Battle CL, Johnson DM, Zlotnick C, Dolan-Sewell R, et al. Traumatic exposure and posttraumatic stress disorder in borderline, schizotypal, avoidant, and obsessive-compulsive personality disorders: findings from the collaborative longitudinal personality disorders study. J Nerv Ment Dis 2002;190(August (8)):510-8.

[43] Silk KR, Lee S, Hill EM, Lohr NE. Borderline personality disorder symptoms and severity of sexual abuse. Am J Psychiatry 1995;152(July (7)):1059-64.

[44] Chu JA, Dill DL. Dissociative symptoms in relation to childhood physical and sexual abuse. Am J Psychiatry 1990;147(July (7)):887-92.

[45] Draijer N, Langeland W. Childhood trauma and perceived parental dysfunction in the etiology of dissociative symptoms in psychiatric inpatients. Am J Psychiatry 1999;156(March (3)):379-85.

[46] Kelleher I, Harley M, Lynch F, Arseneault L, Fitzpatrick C, Cannon M. Associations between childhood trauma, bullying and psychotic symptoms among a school-based adolescent sample. Br J Psychiatry 2008;193(November (5)):378-82.

[47] Wurr CJ, Partridge IM. The prevalence of a history of childhood sexual abuse in an acute adult inpatient population. Child Abuse Negl 1996;20(September (9)):867-72.

[48] Paris J. Does childhood trauma cause personality disorders in adults? Can ] Psychiatry 1998;43(March (2)):148-53.

[49] Bendall S, Jackson HJ, Hulbert CA, McGorry PD. Childhood trauma and psychotic disorders: a systematic, critical review of the evidence. Schizophr Bull 2008;34(May (3)):568-79.

[50] Longden E, Madill A, Waterman MG. Dissociation, trauma, and the role of lived experience: toward a new conceptualization of voice hearing. Psychol Bull 2012;138(January (1)):28-76.

[51] Bozkurt Zincir S, Yanartas O, Zincir S, Semiz UB. Clinical correlates of childhood trauma and dissociative phenomena in patients with severe psychiatric disorders. Psychiatr Q 2014;85(December (4)):417-26.

[52] Pearce J, Simpson J, Berry K, Bucci S, Moskowitz A, Varese F. Attachment and dissociation as mediators of the link between childhood trauma and psychotic experiences. Clin Psychol Psychother 2017(June).

[53] Perona-Garcelan S, Carrascoso-Lopez F, Garcia-Montes JM, Ductor-Recuerda MJ, Lopez Jimenez AM, Vallina-Fernandez O, et al. Dissociative experiences as mediators between childhood trauma and auditory hallucinations. J Trauma Stress 2012;25(June (3)):323-9.

[54] Yamasaki S, Ando S, Koike S, Usami S, Endo K, French P, et al. Dissociation mediates the relationship between peer victimization and hallucinatory experiences among early adolescents. Schizophr Res Cogn 2016;16(May (4)):18-23.

[55] Thompson A, Marwaha S, Nelson B, Wood SJ, McGorry PD, Yung AR, et al. Do affective or dissociative symptoms mediate the association between childhood sexual trauma and transition to psychosis in an ultra-high risk cohort? Psychiatry Res 2016;28(February (236)):182-5.

[56] van Os J, Linscott RJ, Myin-Germeys I, Delespaul P, Krabbendam L. A systematic review and meta-analysis of the psychosis continuum: evidence for a psychosis proneness-persistence-impairment model of psychotic disorder. Psychol Med 2009;39(February (2)):179-95.

[57] Baryshnikov I. Self-reported features of borderline and schizotypal personality disorders in patients with mood disorders. 2017-04-07.

[58] Aaltonen K, Naatanen P, Heikkinen M, Koivisto M, Baryshnikov I, Karpov B, et al. Differences and similarities of risk factors for suicidal ideation and attempts among patients with depressive or bipolar disorders. J Affect Disord 2016;193(March):318-30.
[59] World Health Organization. International classification of disease. 10th ed. 1992 Geneva.

[60] Patterson P, Skeate A, Birchwood M, editors. TADS-EPOS 1.2. Birmingham: University of Birmingham; 2002.

[61] Salokangas RK, Schultze-Lutter F, Patterson P, von Reventlow HG, Heinimaa M, From T, et al. Psychometric properties of the trauma and distress scale, TADS, in an adult community sample in finland. Eur J Psychotraumatol 2016;30(March (7)):30062.

[62] Zanarini MC, Vujanovic AA, Parachini EA, Boulanger JL, Frankenburg FR, Hennen J. A screening measure for BPD: The McLean screening instrument for borderline personality disorder (MSI-BPD). J Pers Disord 2003;17(December (6)):568-73.

[63] Melartin T, Hakkinen M, Koivisto M, Suominen K, Isometsa ET. Screening of psychiatric outpatients for borderline personality disorder with the McLean screening instrument for borderline personality disorder (MSI-BPD). Nord J Psychiatry 2009;63(November (6)):475-9.

[64] Lieb K, Zanarini MC, Schmahl C, Linehan MM, Bohus M. Borderline personality disorder. Lancet 2004:364(9432)453-61 Jul 31-Aug 6.

[65] Mackinnon DP, Lockwood CM, Williams J. Confidence limits for the indirect effect: distribution of the product and resampling methods. Multivariate Behav Res 2004;39(January (1)):99.

[66] Preacher KJ, Hayes AF. Asymptotic and resampling strategies for assessing and comparing indirect effects in multiple mediator models. Behav Res Methods 2008;40(August (3)):879-91.

[67] Baryshnikov I. Self-reported features of borderline and schizotypal personality disorders in patients with mood disorders. 2017-04-07.

[68] Melartin TK, Rytsala HJ, Leskela US, Lestela-Mielonen PS, Sokero TP, Isometsa ET. Current comorbidity of psychiatric disorders among DSM-IV major depressive disorder patients in psychiatric care in the vantaa depression study. J Clin Psychiatry 2002;63(February (2)):126-34.

[69] Mantere O, Suominen K, Leppamaki S, Valtonen H, Arvilommi P, Isometsa E. The clinical characteristics of DSM-IV bipolar I and II disorders: baseline findings from the jorvi bipolar study (JoBS). Bipolar Disord 2004;6(October (5)):395-405.

[70] Hoertnagl CM, Hofer A. Social cognition in serious mental illness. Curr Opin Psychiatry 2014;27(May (3)):197-202.

[71] Talarowska M, Berk M, Maes M, Galecki P. Autobiographical memory dysfunctions in depressive disorders. Psychiatry Clin Neurosci 2016;70 (February (2)):100-8.

[72] Philippi CL, Koenigs M. The neuropsychology of self-reflection in psychiatric illness. J Psychiatr Res 2014;54(July):55-63.

[73] Vermetten E, Spiegel D. Trauma and dissociation: implications for borderline personality disorder. Curr Psychiatry Rep 201416(February (2)) 434,013-04348.

[74] Mosquera D, Gonzalez A, Leeds AM. Early experience, structural dissociation, and emotional dysregulation in borderline personality disorder: the role of insecure and disorganized attachment. Borderline Personal Disord Emot Dysregul 201428(October) 1:15,6673-1-15. eCollection 2014.

[75] Barnow S, Arens EA, Sieswerda S, Dinu-Biringer R, Spitzer C, Lang S. Borderline personality disorder and psychosis: a review. Curr Psychiatry Rep 2010;12 (June (3)):186-95.

[76] Gunderson JG, Singer MT. Defining borderline patients: an overview. Am ] Psychiatry 1975;132(January (1)):1-10.

[77] Gunderson JG. Borderline personality disorder: ontogeny of a diagnosis. Am J Psychiatry 2009;166(May (5)):530-9.

[78] Zanarini MC, Gunderson JG, Frankenburg FR. Cognitive features of borderline personality disorder. Am J Psychiatry 1990;147(January (1)):57-63.

[79] Yee L, Korner AJ, McSwiggan S, Meares RA, Stevenson J. Persistent hallucinosis in borderline personality disorder. Compr Psychiatry 2005;46(March-April (2)):147-54.

[80] Pope Jr. HG, Jonas JM, Hudson JI, Cohen BM, Tohen M. An empirical study of psychosis in borderline personality disorder. Am J Psychiatry 1985;142 (November (11)):1285-90.

[81] Kelleher I, DeVylder JE. Hallucinations in borderline personality disorder and common mental disorders. Br J Psychiatry 2017;210(March (3)):230-1.

[82] Schroeder K, Fisher HL, Schafer I. Psychotic symptoms in patients with borderline personality disorder: prevalence and clinical management. Curr Opin Psychiatry 2013;26(January (1)):113-9.

[83] Tikka M, Luutonen S, Ilonen T, Tuominen L, Kotimaki M, Hankala J, et al. Childhood trauma and premorbid adjustment among individuals at clinical high risk for psychosis and normal control subjects. Early Interv Psychiatry 2013;7(Febraury (1)):51-7.

[84] Bentall RP, de Sousa P, Varese F, Wickham S, Sitko K, Haarmans M, et al. From adversity to psychosis: pathways and mechanisms from specific adversities to specific symptoms. Soc Psychiatry Psychiatr Epidemiol 2014;49(July (7)):1011-22

[85] Dalenberg CJ, Brand BL, Gleaves DH, Dorahy MJ, Loewenstein RJ, Cardena E, et al. Evaluation of the evidence for the trauma and fantasy models of dissociation. Psychol Bull 2012;138(May (3)):550-88.

[86] Kelleher I, Cannon M. Whither the psychosis-Neurosis borderline. Schizophr Bull 2014;40(2)266-8 PMC. Web. 18 Nov. 2017. 